(1)

CrossMark

\section{Could the smoking gun in the fight against COVID-19 be the (rh)ACE-2?}

To the Editor:

Two interesting publications in the European Respiratory Journal recently by Russo et al. [1] and LeUNG et al. [2] discuss the possible role of nicotine in this pandemic and the "furious pursuit for better therapeutics".

Not surprisingly, the angiotensin-converting enzyme 2 (ACE-2) is known to be the likely host receptor for the severe acute respiratory syndrome coronavirus 2 (SARS-CoV-2). Further, at a basic level, cellular mechanisms of nicotinic receptor activity promote SARS-CoV-2 entry and proliferation in epithelial cells through co-expression of ACE-2. Hence, this is the theory postulated by OlDS and KABBANI [3] for how nicotine consumption represents a special risk factor in coronavirus disease 2019 (COVID-19).

On the other hand, and very surprisingly, Changeux et al. [4] hypothesise that the nicotinic receptor also plays a key role in the pathophysiology and might represent a target for the prevention and control of COVID-19 infection. Again, on a basic level, the hypothesis is that the SARS-CoV-2 virus is a nicotinic agent which competes with nicotine for the receptor. The backbone of this hypothesis proposes that under controlled settings, nicotinic agents (such as nicotine patches) could provide an efficient treatment for an acute infection such as COVID-19.

So, tenuously, is the argument centred around the need for data about alternative nicotine delivery systems and their risk/benefit ratio in relation to COVID-19 [5]? Possibly, but are there perhaps other ways...?

Soluble ACE-2 might impact viral spread, since binding to soluble receptor has been shown to block SARS-CoV-2 entry. BATLLE et al. [6] argue that, if given in its soluble form as an appropriate recombinant ACE-2 protein, this may represent a new tool to combat the spread of COVID-19.

Similarly, Guo et al. [7] opined that exogenous supplement of recombinant human (rh)ACE-2 might be a brilliant idea in the treatment of COVID-19. Here the soluble ACE-2 may act as the bait to neutralise the spike protein on the surface of the SARS-CoV-2, thus inhibiting entry. Further, Guo et al. [7] referenced a recent study that demonstrated fusion protein of rhACE-2 (with an Fc fragment) showing high affinity binding to the receptor-binding domain of SARS-CoV-2. This, again, provides a basis for further drug development as fusion protein technology has been very successfully deployed in various therapeutic areas, such as rheumatology and haemophilia.

@ERSpublications

Exogenous supplement of recombinant human (rh)ACE-2 might be a brilliant idea in the treatment of COVID-19. Soluble ACE-2 might impact viral spread, since binding to soluble receptor has been shown to block SARS-CoV-2 entry. https://bit.ly/3bsUKO2

Cite this article as: Lutchman D. Could the smoking gun in the fight against COVID-19 be the (rh)ACE-2? Eur Respir J 2020; 56: 2001560 [https://doi.org/10.1183/13993003.01560-2020].

Dhamend Lutchman (B)

Point Cook, Mebourne, Australia.

Correspondence: Dhamend Lutchman, Point Cook, Melbourne, Australia 3030. E-mail: dlutchman@yahoo.com

Received: 4 May 2020 | Accepted after revision: 6 May 2020

Conflict of interest: None declared.

\section{References}

1 Russo P, Bonassi S, Giacconi R, et al. COVID-19 and smoking: is nicotine the hidden link? Eur Respir J 2020; 55: 2001116.

2 Leung JM, Yang CX, Sin DD. COVID-19 and nicotine as a mediator of ACE-2. Eur Respir J 2020; 55: 2001261.

3 Olds JL, Kabbani N. Is nicotine exposure linked to cardiopulmonary vulnerability to COVID-19 in the general population? FEBS J 2020; in press [https://doi.org/10.1111/febs.15303]. 
4 Changeux JP, Amoura Z, Rey F, et al. A nicotinic hypothesis for Covid-19 with preventive and therapeutic implications. Qeios 2020; preprint [https://doi.org/10.32388/FXGQSB].

5 Berlin I, Thomas D, Le Faou AL, et al. COVID-19 and smoking. Nicotine Tob Res 2020; in press [https://oi.org/ 10.1093/ntr/ntaa059].

6 Batlle D, Wysocki J, Satchell K. Soluble angiotensin-converting enzyme 2: a potential approach for coronavirus infection therapy? Clin Sci 2020; 134: 543-545.

7 Guo J, Huang Z, Lin L, et al. Coronavirus disease 2019 (COVID-19) and cardiovascular disease: a viewpoint on the potential influence of angiotensin-converting enzyme inhibitors/angiotensin receptor blockers on onset and severity of severe acute respiratory syndrome coronavirus 2 infection. J Am Heart Assoc 2020; 9: e016219.

\section{COVID-19 and the nicotinic cholinergic system}

To the Editor:

We have read with great interest the paper by LeUnG et al. [1] published in the European Respiratory Journal, the correspondence by Russo et al. [2], and also the subsequent comment by the first group [3]. Both research teams are reporting increased angiotensin-converting enzyme 2 (ACE-2) expression in airways of current smokers and those with COPD, with important implications for coronavirus disease 2019 (COVID-19) patients. Since ACE-2 has been shown to be the main receptor utilised by severe acute respiratory syndrome coronavirus 2 (SARS-CoV-2) to enter the host cells [2], the authors conclude that nicotine is a risk factor for COVID-19. Russo et al. [2] have shown that nicotine upregulates ACE-2 through $\alpha 7-n A C h R s$ which are present in neuronal and non-neuronal cells. LeUNG et al. [3] provided further evidence in support of this hypothesis and propose the repurposing of $\alpha 7-n A C h R$ antagonists for the pandemic (e.g. methyllycaconitine, $\alpha$-conotoxin), expecting that such treatment will alter ACE-2 expression and prevent SARS-CoV-2 entry.

While this hypothesis is based on laboratory experiments, it is not supported by clinical data. Recent observations on the prevalence of smoking among hospitalised COVID-19 patients have raised some important issues. Many studies, while based on preliminary data and subject to several limitations (e.g. lack of adjustment for confounding factors, possibility for inability to report, inaccurate recording or under-reporting of the smoking status), suggest that the proportion of hospitalised COVID-19 patients who are current smokers is by far lower than expected based on population smoking rates $[4,5]$. In one study, smoking was associated with lower odds of hospitalisation for COVID-19 after adjusting for covariates [6].

To further address this issue, we calculated the pooled prevalence of current smoking in 11 published case series (table 1), nine from China and two from the USA [5-15], and compared it to the expected prevalence based on gender-adjusted and gender- and age-adjusted population smoking rates in each country by estimating the prevalence odds ratio (POR) using random effects meta-analysis. Due to the lack of data on patients' age distribution, the age-adjustment for the expected smoking prevalence was calculated by assuming that all patients were aged $\geqslant 65$ years, since lower smoking prevalence is observed in the elderly compared to younger adult age groups. Population smoking prevalence information was derived from the World Health Organization 2018 Global Adult Tobacco Survey [16] for China, and from the US Centers for Disease Control and Prevention (for gender adjustment) [17] and Statista (for gender and age adjustment) [18]. The pooled prevalence of smoking was 5.3\% (95\% CI 3.2-8.0\%), while the gender adjusted POR was $0.16(95 \%$ CI $0.12-0.23$; $\mathrm{p}<0.001)$ and the gender- and age-adjusted POR was

@ERSpublications

The prevalence of smoking among hospitalised COVID-19 patients is low. COVID-19 manifestations could be linked to impairment of the cholinergic anti-inflammatory pathway. Nicotinic cholinergic agonists should be examined as potential therapeutic options. https://bit.ly/2zfUZ1S

Cite this article as: Farsalinos K, Angelopoulou A, Alexandris N, et al. COVID-19 and the nicotinic cholinergic system Eur Respir J 2020; 56: 2001589 [https://doi.org/10.1183/13993003.01589-2020]. 
TABLE 1 Studies used to estimate the pooled prevalence and the prevalence odds ratio of current smoking among hospitalised coronavirus disease 2019 patients Gender- Gender and Gender-adjusted Gender and

adjusted age-adjusted " age-adjusted "

\begin{tabular}{|c|c|c|c|c|c|c|c|c|c|c|c|}
\hline $\operatorname{CDC}[5]^{\#}$ & USA & 1494 & & & & 27 & $1.8(1.2-2.6)$ & $13.7 \%$ & $8.8 \%$ & $0.12(0.08-0.17)$ & $0.19(0.13-0.29)$ \\
\hline GuAN et al. [7] & China & 1085 & 47 (35-58) & $58.1 \%$ & $41.9 \%$ & 137 & $12.6(10.6-14.6)$ & $30.2 \%$ & $27.3 \%$ & $0.36(0.28-0.44)$ & $0.39(0.31-0.48)$ \\
\hline Chen et al. [8] & China & 274 & $62(44-70)$ & $62.4 \%$ & $37.6 \%$ & 12 & $5.4(2.4-8.3)$ & $32.3 \%$ & $29.0 \%$ & $0.10(0.05-0.19)$ & $0.11(0.06-0.21)$ \\
\hline Zноu et al. [9] & China & 191 & $56(46-67)$ & $62.3 \%$ & $37.7 \%$ & 11 & $5.8(2.5-9.1)$ & $32.3 \%$ & $29.0 \%$ & $0.14(0.07-0.27)$ & $0.15(0.08-0.30)$ \\
\hline Mo et al. [10] & China & 155 & $54(42-66)$ & $55.5 \%$ & $44.5 \%$ & 6 & $3.9(0.9-6.9)$ & $29.0 \%$ & $26.2 \%$ & $0.11(0.04-0.26)$ & $0.11(0.05-0.28)$ \\
\hline ZhANG et al. [11] & China & 140 & 57 (25-87) & $50.7 \%$ & $49.3 \%$ & 2 & $1.4(0.0-3.3)$ & $26.6 \%$ & $24.3 \%$ & $0.04(0.01-0.18)$ & $0.05(0.01-0.19)$ \\
\hline WAN et al. [12] & China & 135 & $47(36-55)$ & $53.3 \%$ & $46.7 \%$ & 9 & $6.7(2.5-10.9)$ & $27.9 \%$ & $25.4 \%$ & $0.20(0.09-0.43)$ & $0.21(0.10-0.46)$ \\
\hline Liv et al. [13] & China & 78 & 38 (33-57) & $50.0 \%$ & $50.0 \%$ & 5 & $6.4(0.1-11.8)$ & $26.3 \%$ & $24.1 \%$ & $0.20(0.07-0.58)$ & $0.22(0.08-0.61)$ \\
\hline Huang et al. [14] & China & 41 & $49(41-58)$ & $73.2 \%$ & $26.8 \%$ & 3 & $7.3(0.0-15.3)$ & $37.5 \%$ & $33.3 \%$ & $0.14(0.04-0.54)$ & $0.16(0.04-0.61)$ \\
\hline ZHANG et al. [15] & China & 645 & $\begin{array}{c}35 \pm 14.2 \\
47 \pm 14\end{array}$ & $50.9 \%$ & $49.1 \%$ & 41 & $6.4(4.6-8.5)$ & $26.7 \%$ & $24.4 \%$ & $0.20(0.14-0.28)$ & $0.21(0.15-0.30)$ \\
\hline Petrilli et al. [6] & USA & 1999 & $62(50-74)$ & $62.6 \%$ & $37.4 \%$ & 104 & $5.1(4.2-6.1)$ & $14.0 \%$ & $9.2 \%$ & $0.33(0.26-0.42)$ & $0.54(0.42-0.69)$ \\
\hline Total (pooled) & & 4743 & & & & 330 & $5.3(3.2-8.0)$ & & & $0.16(0.12-0.23)$ & $0.20(0.14-0.30)$ \\
\hline
\end{tabular}

Random-effects meta-analysis was used. Data for age are presented as median (interquartile range) or mean \pm sD. Data on population smoking prevalence were derived from the World Health Organization 2018 Global Adult Tobacco Survey for China, and from the US Centers for Disease Control and Prevention for gender-specific smoking prevalence and Statista for gender specific smoking prevalence in adults aged $\geqslant 65$ years for the USA. "\#: no data about patients' age and gender was available; thus, the unadjusted population prevalence of smoking in the USA was used to calculate the expected number of smokers; " : since the age distribution of patients was not available, age-adjusted smoking prevalence was calculated for all studies by assuming that all patients were aged $\geqslant 65$ years. 
0.20 (95\% CI 0.14-0.30; $\mathrm{p}<0.001$ ). Despite the many limitations, these observations need to be taken into consideration. Recently, a hypothesis that the nicotinic cholinergic system may be involved in COVID-19 infection was presented, based on the fact that several of the symptoms and clinical signs of COVID-19, including the cytokine storm, could be explained by dysfunction of the cholinergic anti-inflammatory pathway [19]. $\alpha 7-n A C h R s$ are potentially involved in modulating pro-inflammatory cytokine secretion and suppressing the cytokine storm [20,21]. Additional clinical manifestations of COVID-19 (such as anosmia and thromboembolic complications) can also be associated with dysfunction of the nicotinic cholinergic system [19].

In conclusion, the observations of a low smoking prevalence among hospitalised COVID-19 patients, despite the important limitations, together with the hypothetical links between dysfunction of the nicotinic cholinergic system and clinical manifestations of the disease raise some important research questions, considering that nicotine is a cholinergic agonist. The interaction between SARS-CoV-2 and the nicotinic cholinergic system should be further examined and any proposal for the repurposing of $\alpha 7-n A C h R$ antagonists should be approached with caution, since it could potentially propagate the cytokine storm and adversely affect the prognosis. Obviously, smoking cannot be considered protective for COVID-19 (or any other disease), but pharmaceutical nicotine products are widely available and their role in COVID-19 should be explored.

Konstantinos Farsalinos $(\mathbb{D}$, Athina Angelopoulou $(\mathbb{D}$, Nikos Alexandris $(\mathbb{D})$ and Konstantinos Poulas Laboratory of Molecular Biology and Immunology, Dept of Pharmacy, University of Patras, Patras, Greece.

Correspondence: Konstantinos Farsalinos, Leoforos Alexandras 196A, Athens 11521, Greece.

E-mail: kfarsalinos@gmail.com

Received: 5 May 2020 | Accepted after revision: 10 May 2020

Conflict of interest: None declared.

\section{References}

1 Leung JM, Yang CX, Tam A, et al. ACE-2 expression in the small airway epithelia of smokers and COPD patients: implications for COVID-19. Eur Respir J 2020; 55: 200688.

2 Russo P, Bonassi S, Giacconi R, et al. COVID-19 and smoking: is nicotine the hidden link? Eur Respir J 2020; 55: 2001116.

3 Leung JM, Yang CX, Sin DD. COVID-19 and nicotine as a mediator of ACE-2. Eur Respir J 2020; 55: 2001261.

4 Farsalinos K, Barbouni A, Niaura R. Systematic review of the prevalence of current smoking among hospitalized COVID-19 patients in China: could nicotine be a therapeutic option? Intern Emerg Med 2020; in press [https:// doi.org/10.1007/s11739-020-02355-7].

5 Centers for Disease Control and Prevention. Preliminary estimates of the prevalence of selected underlying health conditions among patients with coronavirus disease 2019 - United States, February 12-March 28, 2020. MMWR Morb Mortal Wkly Rep 2020; 69: 382-386.

6 Petrilli CM, Jones SA, Yang J, et al. Factors associated with hospitalization and critical illness among 4,103 patients with COVID-19 disease in New York City. medRxiv 2020; preprint [https://doi.org/10.1101/ 2020.04.08.20057794].

7 Guan W-J, Ni Z-Y, Hu Y, et al. Clinical characteristics of coronavirus disease 2019 in China. N Engl J Med 2020; 382: $1708-1720$.

8 Chen T, Wu D, Chen $\mathrm{H}$, et al. Clinical characteristics of 113 deceased patients with coronavirus disease 2019: retrospective study. BMJ 2020; 368: m1091.

9 Zhou F, Yu T, Du R, et al. Clinical course and risk factors for mortality of adult inpatients with COVID-19 in Wuhan, China: a retrospective cohort study. Lancet 2020; 395: 1054-1062.

10 Mo P, Xing Y, Xiao Y, et al. Clinical characteristics of refractory COVID-19 pneumonia in Wuhan, China. Clin Infect Dis 2020; in press [https://doi.org/10.1093/cid/ciaa270].

11 Zhang JJ, Dong X, Cao YY, et al. Clinical characteristics of 140 patients infected with SARS-CoV-2 in Wuhan, China. Allergy 2020; in press [https://doi.org/10.1111/all.14238].

12 Wan S, Xiang Y, Fang W, et al. Clinical features and treatment of COVID-19 patients in northeast Chongqing. J Med Virol 2020; 92: 797-806.

13 Liu W, Tao Z-W, Lei W, et al. Analysis of factors associated with disease outcomes in hospitalized patients with 2019 novel coronavirus disease. Chin Med J (Engl) 2020; 133: 1032-1038.

14 Huang C, Wang Y, Li X, et al. Clinical features of patients infected with 2019 novel coronavirus in Wuhan, China. Lancet 2020; 395: 497-506.

15 Zhang X, Cai H, Hu J, et al. Epidemiological, clinical characteristics of cases of SARS-CoV-2 infection with abnormal imaging findings. Int $J$ Infect Dis 2020; 94: 81-87.

16 World Health Organization. Global Adult Tobacco Survey. Fact sheet China 2018. www.who.int/docs/ default-source/wpro---documents/countries/china/2018-gats-china-factsheet-cn-en.pdf?sfvrsn=3f4e2da9_2 Date last accessed: 6 May, 2020.

17 Creamer MR, Wang TW, Babb S, et al. Tobacco product use and cessation indicators among adults - United States, 2018. MMWR Morb Mortal Wkly Rep 2019; 68: 1013-1019.

18 Statista. Percentage of adults in the US who were current cigarette smokers as of 2016, by age and gender. www. statista.com/statistics/673619/smoking-prevalence-among-men-us-by-age/ Date last accessed: 6 May, 2020. 
19 Farsalinos K, Niaura R, Le Houezec J, et al. Nicotine and SARS-CoV-2: COVID-19 may be a disease of the nicotinic cholinergic system. Toxicol Rep 2020; 30: 658-663.

20 Tracey KJ. The inflammatory reflex. Nature 2002; 420: 853-859.

21 Kalamida D, Poulas K, Avramopoulou V, et al. Muscle and neuronal nicotinic acetylcholine receptors: structure, function and pathogenicity. FEBS J 2007; 274: 3799-3845.

\title{
COVID-19 and vaping: risk for increased susceptibility to SARS-CoV-2 infection?
}

\author{
To the Editor:
}

With great interest we read and commend the study done by Russo et al. [1], highlighting their findings that nicotine induces an increase in angiotensin-converting enzyme 2 (ACE-2) expression in human bronchial epithelial cells (HBEpC) and is mediated by $\alpha 7$-subtype nicotinic receptors ( $\alpha 7$-nAChR). It raises the concern that all electronic nicotine-delivery systems may put users at greater risk of succumbing to coronavirus disease 2019 (COVID-19).

We [2], along with LeUng et al. [3], have shown that ACE-2 expression is upregulated in the small airway epithelia of smokers and patients with COPD. In particular, we observed increased ACE-2 expression in type-2 pneumocytes and alveolar macrophages along with the small airway epithelium of smokers compared to healthy never-smokers [2]. Similar studies are yet to be done in the context of electronic cigarettes (e-cigarettes), heat-not-burn devices (IQOS) or waterpipe exposure to human airways. ACE-2 is the binding site for severe acute respiratory syndrome coronavirus 2 (SARS-CoV-2), mediating entry of the virus into cells [4]. Binding affinity between the spike proteins of the virus and ACE-2 on respiratory cells has been identified to be much higher than any previously identified human coronavirus. The significance of such overexpression of ACE-2 in smokers should not be ignored. COVID-19 and progression of severe pneumonia may be more likely to occur in smokers, particularly in those that have smoking-related comorbidities [5]. We are beginning to elucidate the role of traditional cigarette smoking and nicotine-driven changes to the lungs in the context of coronavirus transmission and susceptibility. Cigarette smoke has been identified and linked to increasing expression of the binding site for the cause of the 2020 pandemic (SARS-CoV-2) via mediating nicotine receptors. With this, an avoidable and potentially gigantic risk-factor has emerged for COVID-19, as the pandemic continues to claim ultimate grasp over the year of 2020 .

Here, we bring to the discussion whether the increased susceptibility and virulence of SARS-CoV-2 via $\alpha 7-n A C h R$ and the upregulation of small airway ACE-2 expression may also be relevant for those who vape using nicotine-based e-cigarettes. E-cigarette vapour studies, although in their infancy, have already shown that they can enhance the virulence and inflammatory profile of pathogens such as Streptococcus pneumoniae, among other deleterious biological effects [6]. Vaping intensifies pneumococcal adherence through an increase in platelet-activating factor receptor expression, ultimately rendering those who vape with an increased risk of pneumonia $[7,8]$. We, among others, have previously shown that e-cigarettes and IQOS are not "safer", as having a vast pro-inflammatory response [9]. We compared cigarette smoke versus e-cigarette and IQOS on airway epithelial and smooth muscle cells [9]. All tested pathological biomarkers were elevated in cells exposed to e-cigarette aerosols and IQOS, which included chemokine CXCL8, extracellular matrix proteins and markers of mitochondrial dysfunction. We found these products toxic to the cells, evident from decreased cellular viability and integrity. More devastatingly, vaping also interfered with cellular energetics. Our results further substantiate current research that e-cigarettes and

@ERSpublications

Absolute cessation of any tobacco product in any form: implications for COVID-19 https://bit.ly/ 3cyk9ra

Cite this article as: McAlinden KD, Eapen MS, Lu W, et al. COVID-19 and vaping: risk for increased susceptibility to SARS-CoV-2 infection? Eur Respir J 2020; 56: 2001645 [https://doi.org/10.1183/ 13993003.01645-2020]. 
IOQS are indeed detrimental with increases in oxidative stress, inflammation, infections and airway remodelling in the lungs of these device users. As the scientific evidence mounts, confirming the fears that e-cigarettes and IQOS are strongly associated with the development and progression of debilitating lung diseases [10], now may be the prime time to include all electronic nicotine delivery systems in the vocalisation of concerns concerning tobacco-related death and disease.

We recirculate the simple notion that the lungs are not designed for the chronic inhalation of anything but air and that the indication for a smoking- and nicotine-induced increase in ACE2 is more evidence to the stacking weight of toxicity that tobacco is for humanity. Given the role of the nicotine receptor, vaping may also lead to the upregulation of ACE-2. Research in this area will be invaluable in the development of e-cigarette research and providing trusted, peer-reviewed and real evidence for the youth of the 2020s. We strongly recommend that the World Health Organization and countries act to advance their efforts to reduce smoking, vaping and waterpipe use. During a pandemic it is difficult to focus on anything other than the immediate threat. The "primacy of rescue" has overwhelmed preventive action. Additional research into the relationship of smoking, and all electronic nicotine delivery systems to the infection, transmission and progression of COVID-19 is required. Progress towards easily identifying those susceptible to severe disease or capable of asymptomatic transmission are important goals for managing the disease at a community level. COVID-19 is a dress rehearsal for the next pandemic, and the next, and the one after that: the new norm.

Kielan Darcy McAlinden ${ }^{1}$, Mathew Suji Eapen $\oplus^{1}$, Wenying $\mathrm{Lu}^{1}$, Collin Chia ${ }^{1,2}$, Greg Haug ${ }^{1,2}$ and Sukhwinder Singh Sohal

${ }^{1}$ Respiratory Translational Research Group, Department of Laboratory Medicine, School of Health Sciences, College of Health and Medicine, University of Tasmania, Launceston, Australia. ${ }^{2}$ Department of Respiratory Medicine, Launceston General Hospital, Launceston, Australia.

Correspondence: Sukhwinder Singh Sohal, Respiratory Translational Research Group, Department of Laboratory Medicine, School of Health Sciences, College of Health and Medicine, University of Tasmania, Locked Bag - 1322, Newnham Drive, Launceston, Tasmania 7248, Australia. E-mail: sssohal@utas.edu.au

Received: 7 May 2020 | Accepted after revision: 10 May 2020

Acknowledgements: Clifford Craig Foundation Launceston General Hospital, Rebecca L. Cooper Medical Research Foundation.

Conflict of interest: None declared.

\section{References}

1 Russo P, Bonassi S, Giacconi R, et al. COVID-19 and smoking: is nicotine the hidden link? Eur Respir J 2020; 55: 2001116.

2 Brake SJ, Barnsley $\mathrm{K}, \mathrm{Lu} \mathrm{W}$, et al. Smoking upregulates angiotensin-converting enzyme-2 receptor: a potential adhesion site for novel coronavirus SARS-CoV-2 (Covid-19). J Clin Med 2020; 9: 841.

3 Leung JM, Yang CX, Tam A, et al. ACE-2 expression in the small airway epithelia of smokers and COPD patients: implications for COVID-19. Eur Respir J 2020; 55: 200688.

4 Wrapp D, Wang N, Corbett KS, et al. Cryo-EM structure of the 2019-nCoV spike in the prefusion conformation. Science 2020; 367: 1260-1263.

5 Liu W, Tao Z-W, Wang L, et al. Analysis of factors associated with disease outcomes in hospitalized patients with 2019 novel coronavirus disease. Chin Med J 2020; 133: 1032-1038.

6 Gilpin DF, McGown KA, Gallagher K, et al. Electronic cigarette vapour increases virulence and inflammatory potential of respiratory pathogens. Respir Res 2019; 20: 267.

7 Miyashita L, Suri R, Dearing E, et al. E-cigarette vapour enhances pneumococcal adherence to airway epithelial cells. Eur Respir J 2018; 51: 1701592.

8 Atto B, Eapen MS, Sharma P, et al. New therapeutic targets for the prevention of infectious acute exacerbations of COPD: role of epithelial adhesion molecules and inflammatory pathways. Clin Sci 2019; 133: 1663-1703.

9 Sohal SS, Eapen MS, Naidu VGM, et al. IQOS exposure impairs human airway cell homeostasis: direct comparison with traditional cigarette and e-cigarette. ERJ Open Res 2019; 5: 00159-2018.

10 McAlinden KD, Sohal SS, Sharma P. There can be smoke without fire: warranted caution in promoting electronic cigarettes and heat not burn devices as a safer alternative to cigarette smoking. ERJ Open Res 2019; 5: 00114-2019. 


\section{Smoking, ACE-2 and COVID-19: ongoing controversies}

From the authors:

The three letters from D. Lutchman, K.D. McAlinden and co-workers, and K. Farsalinos and co-workers together capture the divergence in opinion on the impact of smoking on coronavirus disease 2019 (COVID-19) and whether the angiotensin-converting enzyme 2 (ACE-2) receptor mediates this relationship. At the heart of this controversy is whether smoking reduces or increases the risk of contracting COVID-19. K. Farsalinos and co-workers, through analysis of the pooled prevalence of current smoking across 11 case series determined that current smoking status was significantly lower than expected gender- and age-adjusted prevalence in COVID-19 patients. That smoking could potentially be protective against COVID-19 has not gone unnoticed by the public. Since late April, multiple media outlets have reported on this possibility, prompting the World Health Organization (WHO) to release a warning on 4 May, 2020, on tobacco use during this pandemic [1]. While we do not dispute that the prevalence of smoking in COVID-19 cases has been surprisingly low across the world, we would echo WHO's advice, based on emerging evidence that outcomes in COVID-19 are worse in patients who do smoke. An analysis conducted by KilLerby et al. [2], of 220 hospitalised and 311 nonhospitalised patients with COVID-19 patients across six acute care hospitals and associated outpatient clinics in metropolitan Atlanta, Georgia, for instance, demonstrated that smoking was an independent risk factor for COVID-19 hospitalisation, carrying an odds ratio of 2.3 (95\% CI 1.2-4.5). A recent meta-analysis has also shown that smokers have a relative risk of 1.34 (95\% CI 1.07-1.67) of having more severe disease or experiencing refractory or progressive disease [3]. While smoking may not necessarily increase one's risk for contracting COVID-19, the biological and inflammatory cascade that occurs upon severe acute respiratory syndrome coronavirus 2 (SARS-CoV-2) infection may be particularly devastating for a smoker.

K.D. McAlinden and co-workers raise the possibility that a similar effect could be occurring in patients who vape. Certainly, the risks of significant pulmonary injury with vaping are now well-described in the literature [4], and the multiple ways that vaping can cause cellular damage and impede the lung's response to infection are clearly delineated by the authors. The theoretical possibility that vaping could prime the lung for SARS-CoV-2 infection is still hypothetical, given that to date none of the epidemiological studies have reported on vaping prevalence amongst their COVID-19 patients. Several demographic factors, however, make such estimates unlikely to be obtained with much precision. For instance, consider the landscape of e-cigarette use in China, the first epicentre of COVID-19. A 2018 survey of 10233 individuals in five Chinese cities found that only $0.9 \%$ had used e-cigarettes within the past 30 days [5]. Only $0.2 \%$ of those 65 years and older reported e-cigarette use within the past 30 days compared to $1.5 \%$ of those in the 15-24 year age range. Similarly, in 2016, of 32931 adults included in the US National Health Interview Survey, $1.0 \%$ of those over 65 years reported current e-cigarette use compared to $4.6 \%$ of the $18-44$ year age group [6]. Older age groups, the ones more likely to have severe COVID-19, present to a hospital, and therefore be captured by epidemiologists in their surveys, are therefore less likely to report current vaping. On the other hand, it may be difficult to ascertain the prevalence of vaping in younger age groups who are much more likely to vape, but also much more likely to have mild or asymptomatic COVID-19 infections that are not captured, either for their failure to present to a healthcare provider or the constraints placed on available tests in resource-limited settings. Nonetheless, we would argue for hospitals to capture these data as best they can and hope that data for mild cases in younger outpatients begin to be reported from around the world. Similar to smoking, it is possible that vaping may still be associated with worse outcomes, if not necessarily being a risk factor for contracting infection in the first place.

Finally, as D. Lutchman notes, if the culprit player for worse outcomes in smokers in this pandemic is the heightened ACE-2 receptor in the airway epithelium, soluble ACE-2 might be a therapeutic option. Indeed, we would agree with the excitement for this approach as this was the subject of a recent study by MoNTEIL 
et al. [7], which showed that human recombinant soluble ACE-2 (hrsACE-2) reduced SARS-CoV-2 viral loads in infected Vero-E6 cells by a factor of 1000-5000. hrsACE-2 also inhibited SARS-CoV-2 infections of kidney and vascular organoids. hrsACE-2 is now under phase 2 investigation in Europe as a therapeutic agent for COVID-19 (ClinicalTrials.gov: NCT04335136). Whether such a therapy will be helpful for the smokers and patients with COPD who display higher levels of ACE-2 in their airways and may suffer worse outcomes from COVID-19 remains to be determined.

Janice M. Leung and Don D. Sin

Centre for Heart Lung Innovation and the Division of Respiratory Medicine, St. Paul's Hospital, University of British Columbia, Vancouver, BC, Canada.

Correspondence: Don D. Sin, Centre for Heart Lung Innovation, St. Paul's Hospital, University of British Columbia, 1081 Burrard Street, Vancouver, BC, V6Z 1Y6, Canada. E-mail: Don.Sin@hli.ubc.ca

Received: 13 May 2020 | Accepted: 13 May 2020

Conflict of interest: J.M. Leung has nothing to disclose. D.D. Sin reports grants from Merck, personal fees for advisory board work from Sanofi-Aventis and Regeneron, grants and personal fees for research from Boehringer Ingelheim, grants and personal fees for lectures and advisory board work from AstraZeneca, personal fees for lectures and advisory board work from Novartis, outside the submitted work.

\section{References}

1 World Health Organization. Tobacco Users May Be at an Increased Risk of \#COVID19, both in Contracting the Disease and Complications. https://twitter.com/WHO_Europe/status/1257255102634745857 Date last accessed: 10 May 2020.

2 Killerby ME, Link-Gelles R, Haight SC, et al. Characteristics associated with hospitalization among patients with COVID-19 - Metropolitan Atlanta, Georgia, March-April 2020. MMWR Morb Mortal Wkly Rep 2020; 69: 790-794.

3 Karanasos A, Aznaouridis K, Latsios G, et al. Impact of smoking status on disease severity and mortality of hospitalized patients with COVID-19 infection: a systematic review and meta-analysis. Nicotine Tob Res 2020; in press [https://doi.org/10.1093/ntr/ntaa107].

4 Werner AK, Koumans EH, Chatham-Stephens K, et al. Hospitalizations and deaths associated with EVALI. $N$ Engl J Med 2020; 382: 1589-1598.

5 Huang J, Duan Z, Wang Y, et al. Use of electronic nicotine delivery systems (ENDS) in China: evidence from citywide representative surveys from five Chinese cities in 2018. Int J Environ Res Public Health 2020; 17: E2541.

6 Bao W, Xu G, Lu J, et al. Changes in electronic cigarette use among adults in the United States, 2014-2016. JAMA 2018; 319: 2039-2041.

7 Monteil V, Kwon H, Prado P, et al. Inhibition of SARS-CoV-2 infections in engineered human tissues using clinical-grade soluble human ACE2. Cell 2020; 181: 905-913. 